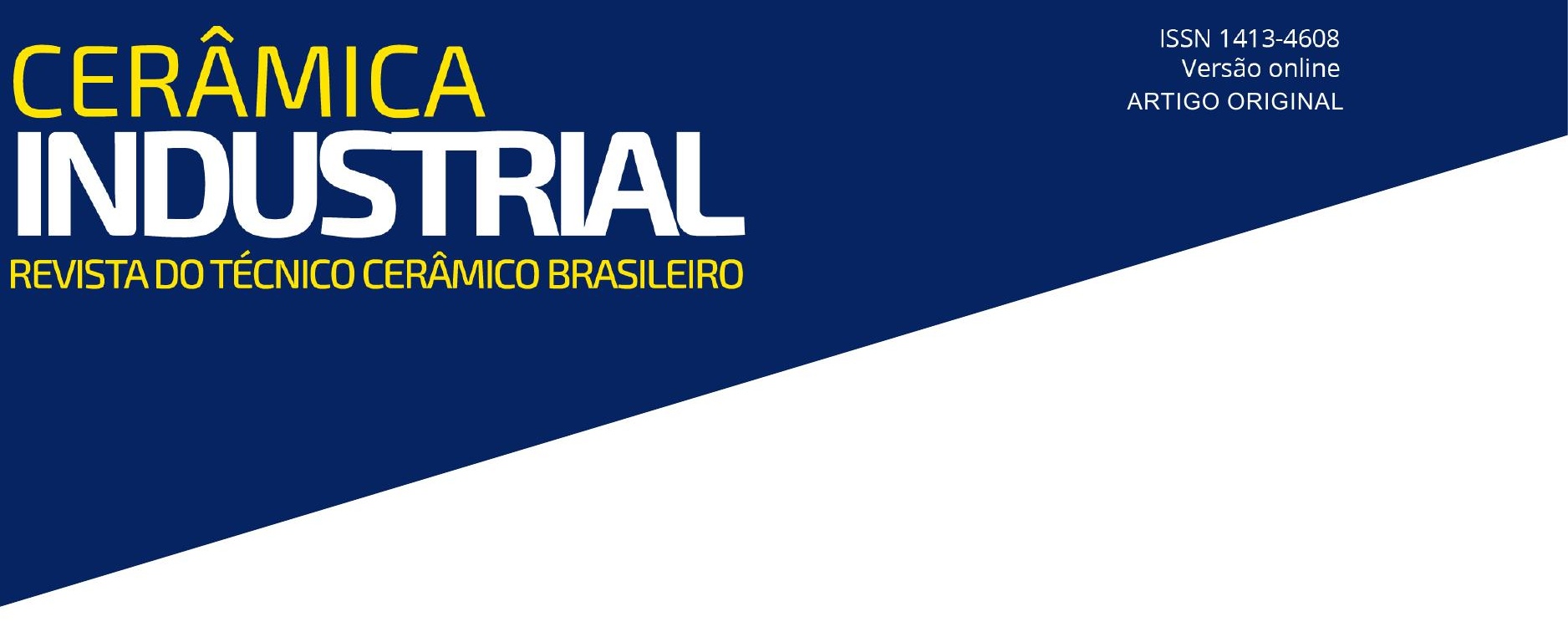

\title{
Obtenção de cerâmica de revestimento sustentável desenvolvida com resíduos industriais
}

\author{
A. L. A. Caetano a, V. C. Marques ${ }^{a}$, D. A. de Macedo ${ }^{a}$, H. S. Ferreiraa, R. P. S. Dutraa , R. R. N. Menezes ${ }^{a}$ \\ aUniversidade Federal da Paraíba, Campus I, Centro de Tecnologia, Departamento de Engenharia de Materiais, João Pessoa, \\ PB, Brazil, CEP: 58051-900 \\ *e-mail: veronicacavalcante87@hotmail.com
}

\begin{abstract}
Resumo
O crescimento dos impactos ambientais ocasionado pelos resíduos descartados no meio ambiente desperta grande interesse entre os pesquisadores, a fim de buscar soluções. Os custos de disposição de resíduos de forma ecologicamente correta são muito elevados, o que tem motivado a busca por alternativas tecnológicas viáveis para a reutilização de resíduos industriais, tanto na reintrodução dos ciclos industriais já existentes, quanto na produção de novos produtos, os quais podem assumir lugares de destaque em vários segmentos, sendo um dos mais importantes e principais, a indústria da construção civil. Este trabalho tem por objetivo caracterizar e combinar matérias-primas alternativas, como resíduos advindos de ciclos industriais para obtenção de cerâmica de revestimento que atenda as exigências da norma ABNT NBR ISO 10545-2:2020, a qual fixa as características exigíveis para esse tipo de material. Os resíduos foram caracterizados por técnicas de análise química, mineralógica, térmica e granulométrica. Formulações cerâmicas contendo resíduos de caulim, granito e polimento do porcelanato foram produzidas por prensagem e sinterizadas em três diferentes temperaturas. As amostras sinterizadas foram caracterizadas por ensaios de absorção de água, perda ao fogo, retração linear de queima e tensão de ruptura à flexão. Os resultados indicaram que o resíduo do caulim é constituído por caulinita, mica e quartzo. O resíduo de granito é constituído por quartzo, mica, anortita e magnesiorblenda. O resíduo do polimento de porcelanato é constituído por mulita, quartzo e carbeto de silício. Os resíduos apresentam distribuições granulométricas significativamente diferentes. A análise das propriedades tecnológicas, as quais as diferentes combinações de resíduos foram submetidas, demonstra que os produtos obtidos se adequam as exigências da norma NBR 6502/1995 e podem ser classificados como revestimentos cerâmicos semiporoso e poroso.
\end{abstract}

Palavras-chave: resíduos, reaproveitamento, caulim, granito, porcelanato, revestimentos cerâmicos.

\section{INTRODUÇÃO:}

As indústrias de beneficiamento de minérios e revestimentos cerâmicos são segmentos industriais muito importantes em todos os estados produtores do Brasil. Atualmente os resíduos industriais são um grave problema para a sociedade. Os descartes desses resíduos feitos de forma inadequada poluem a natureza, vegetações, rios, várzeas, e até lençóis freáticos contaminando a água que poderia ser consumida pela população [1-3].

A reciclagem e reutilização do resíduo produzido por estas indústrias, depois de detectadas suas potencialidades, é considerada uma excelente alternativa de matéria-prima para fabricação de produtos cerâmicos, podendo contribuir para a diversificação de produtos, com diminuição dos custos 
de produção, com a conservação dos atuais recursos não renováveis, com a economia de energia e principalmente contribuindo para a preservação do meio ambiente $[4,5]$.

A indústria da mineração e beneficiamento de caulim do estado da Paraíba produz milhares de toneladas de caulim por ano, sendo um importante segmento econômico em várias regiões do estado. Entretanto, a indústria do caulim também produz uma elevada quantidade de resíduos. Dois tipos de resíduos são gerados por essa indústria; um "grosso" (com tamanho de partículas > 200 $\mu \mathrm{m}$ ), que é constituído basicamente por quartzo e é gerado na primeira etapa do beneficiamento do caulim, e um "fino" que é oriundo da etapa de purificação do caulim através de processos de separação a úmido do caulim da ganga do minério. Esses resíduos são geralmente descartados no meio ambiente, causando danos à fauna, à flora e à saúde da população. No beneficiamento do granito não é diferente, sendo originados centenas de toneladas de resíduos no meio ambiente, quais sejam: pó de pedra, fragmentos de rocha nas pedreiras e serrarias e a lama abrasiva que podem provocar impactos consideráveis no solo, lagos e córregos, pois não são descartados de forma responsável [6].

Durante a etapa de polimento do porcelanato são geradas grandes quantidades de resíduos, gerando custos aos produtores do setor, que por sua vez, necessitam gerenciar e descartar adequadamente esses resíduos. O resíduo do polimento do porcelanato, por sua vez, é constituído de uma mistura de material cerâmico oriundo do polimento do porcelanato e material abrasivo, geralmente composto por partículas de diamante ou carbeto de silício aglomerados por cimentos à base de cloretos magnesianos [7].

Na fabricação de revestimentos cerâmicos não existe uma única matéria-prima natural que venha a apresentar todas as características necessárias para que ocorra uma boa formulação, uma boa fundência, uma boa estabilidade dimensional, entre outras características. Portanto, é necessário a utilização de uma mistura de matérias-primas para se obter as características desejadas de uma massa cerâmica [8].

As massas cerâmicas utilizadas em revestimentos cerâmicos apresentam grande variação de composição que por muitas vezes são semelhantes química e fisicamente a diversos resíduos industriais, as quais, normalmente, são enquadradas em três grupos principais: o grupo dos materiais argilosos, que apresentam como principal função fornecer plasticidade a massa verde; o grupo dos materiais refratários, ou inerte para tal condição de tratamento térmico, com função estrutural e; o grupo dos materiais fundentes, que aceleram a cinética de sinterização, diminuindo a temperatura de formação de fase vítrea e contribuindo para a densificação do sinterizado.

O Brasil ocupa lugar de destaque no segmento de revestimento cerâmico, sendo o segundo maior produtor mundial. O setor vem apresentando um grande crescimento, chegando a uma produção de aproximadamente 935 milhões de $\mathrm{m}^{2} / a n o$. No país, o setor conta com 54 empresas e 71 plantas industriais instaladas, distribuídas em mais de 18 estados. $O$ crescente desenvolvimento mundial dos materiais cerâmicos nos últimos anos fez com que o conhecimento científico e tecnológico se tornasse cada vez mais necessário. A competitividade acirrada entre os fabricantes de revestimentos cerâmicos impõe medidas para redução de seus custos de produção e manutenção dos padrões de qualidade, atendendo as normas propostas pelos órgãos nacionais e internacionais de controle de qualidade [9-11].

Em virtude de possuir elevado volume de produção que possibilita a geração de grandes quantidades de rejeitos e que, aliado às características físico-químicas das matérias-primas cerâmicas e às particularidades do processamento cerâmico, faz da indústria cerâmica uma das grandes opções para a reciclagem de resíduos sólidos, e é uma das que mais se destacam nesse ramo. Ademais, é uma das poucas áreas industriais que pode obter vantagens no seu processo produtivo com a incorporação de resíduos entre suas matérias-primas, a exemplo da economia de matérias-primas de elevada qualidade, cada dia mais escassas e caras, a diversificação da oferta de matérias-primas, e a redução do consumo de energia e, por conseguinte, redução de custos. Esse potencial de incorporação de resíduos nas formulações de cerâmicas de revestimento, aliado às elevadas quantidades de recursos naturais consumidos a cada dia por esse segmento industrial, ressalta a importância da reutilização de resíduos como matérias-primas cerâmicas alternativas, racionalizando o uso dos recursos naturais [12,13].

Vários estudos demonstraram a viabilidade de incorporação de resíduos em formulações de massas cerâmicas. Entretanto, não é comum encontrar estudos que avaliam a adição de mais de um resíduo simultaneamente. Através de buscas na literatura, observam-se pesquisas referentes à incorporação de uma variedade de resíduos, tais como: resíduos de polimento do porcelanato $[2,13]$, resíduos de 
lama de alto forno [14], pó de granito [15], cinza de lenha, lodo de estação de tratamento de água e cinza de casca de arroz [16], entre outros.

Trabalhos anteriores $[17,18]$ demonstraram o potencial do uso do resíduo do beneficiamento do caulim como matéria-prima para a produção de corpos cerâmicos porosos e revestimentos.

Pesquisadores estudaram a utilização de resíduos de granito na produção de cerâmica branca. Com incorporação do resíduo à argila houve um aumento da resistência à flexão dos corpos de prova queimados nas temperaturas de 1100 a $1200^{\circ} \mathrm{C}$ [19]. A utilização dos resíduos do polimento de porcelanato em massa cerâmica constatou que a adição de 3,0 e 5,0\% de resíduo na formulação comercial para produção de porcelanato reduz a temperatura ótima de queima em 25 e $50^{\circ} \mathrm{C}$, respectivamente, e provoca um leve aumento na densidade aparente dos corpos de prova [7].

A reintegração dos resíduos citados anteriormente ao processo produtivo tem consequências positivas por retirar do meio ambiente materiais danosos à saúde da população, possibilitar as indústrias produtoras de revestimentos utilizar resíduos como matérias-primas de baixo custo, bem como oferecer ao gerador dos resíduos condições de mercado para um produto que estaria ocioso ou gerando despesas de armazenamento. Neste contexto, este trabalho teve como objetivo caracterizar três diferentes tipos de resíduos industriais (resíduo do beneficiamento do caulim, resíduo de granito e resíduo do polimento de porcelanato), visando a formulação e utilização destes resíduos como matérias-primas para obtenção de revestimentos cerâmicos.

\section{MATERIAIS E MÉTODOS}

\subsection{Materiais}

O resíduo de caulim $(R C)$ usado neste trabalho foi procedente da etapa final do beneficiamento do caulim, considerado como "fração fina do resíduo", fornecido pela indústria MP Beneficiamento e Comércio de Caulim LTDA, Juazeirinho - Paraíba. O resíduo de granito (RG) foi fornecido pela indústria Granfugi Mármores e Granito LTDA, Campina Grande - Paraíba, Brasil. Este resíduo é constituído por frações sólidas procedentes de todos os processos do beneficiamento do granito, inclusive da etapa de polimento, o qual foi coletado dos tanques de decantação do pátio da empresa. O resíduo do polimento do porcelanato (RP) foi fornecido por uma indústria cerâmica, localizada no município do Conde - Paraíba, Brasil, procedente da etapa final do processo de fabricação de revestimento cerâmicos, tipo porcelanato polido.

\subsection{Métodos}

As amostras dos resíduos foram secas em estufa a $60^{\circ} \mathrm{C}$ e classificadas em peneiras de malha 35 mesh (ABNT $\mathrm{n}^{\circ} 40$ ). Foram caracterizadas por meio de técnicas de difração de raios-X (DRX) em difratômetro de raios-X, XRD 6000 da Shimadzu, de fluorescência de raios-X (FRX) em espectrômetro modelo FRX 1800 da Shimadzu, termogravimétrica (TG) e análise térmica diferencial (DTA) em equipamento TA 60H da Shimadzu, e granulometria a Laser em um granulômetro da marca CILAS, modelo 1064, em modo úmido. Em seguida foram preparadas diferentes combinações de resíduos através de uma mistura a seco dos diferentes tipos de resíduos em moinhos de bolas do tipo "periquito", com teores determinados de acordo com as quantidades de óxidos presentes em cada resíduo, estudadas a partir das caracterizações microestruturais de cada um, com a finalidade de formação de corpos prova para revestimento cerâmico (Tab.1), porém, sem que houvesse um delineamento de mistura prévio. Após as etapas de mistura por 5 min, as formulações obtidas foram submetidas às seguintes etapas de preparação para confecção de corpos de provas: correção do teor de umidade para 8\% e conformação por prensagem uniaxial com carga de 3,0 toneladas. Foram confeccionados 3 corpos de prova para cada formulação. Foi utilizada uma massa de $13 \mathrm{~g}$ de cada material em molde metálico prismático com seção interna de $6,0 \mathrm{~cm}$ por $2,0 \mathrm{~cm}$. Posteriormente, todos os corpos de prova foram identificados e medidas as suas dimensões e massas com uso de paquímetro $(150 \mathrm{~mm} / 0,01 \mathrm{~mm})$ e balança $(2 \mathrm{~kg} / 0,01 \mathrm{~g})$, respectivamente. Por fim, foi realizada a secagem dos corpos de prova em estufa com temperatura de $100^{\circ} \mathrm{C} \pm 5^{\circ} \mathrm{C}$ pelo período de 24 horas e na etapa de queima utilizou-se uma taxa de aquecimento de $10^{\circ} \mathrm{C} / \mathrm{min}$ e patamar final de 30 min nas temperaturas de 1000,1100 e $1150^{\circ} \mathrm{C}$. Após o processo de sinterização, os corpos de prova foram submetidos a ensaios tecnológicos para determinação das propriedades tecnológicas e físico-mecânicas de absorção de água (AA), perda ao fogo (PF), retração linear (RL) e tensão de ruptura 
a flexão em três pontos (TRF), segundo critérios previstos pela norma ABNT NBR ISO 10545-2:2020, para averiguar se os comportamentos das peças cerâmicas finais obtidas a partir da mistura de resíduos industriais se adequam aos previstos na norma, além disso, foi realizada uma segunda difratometria de raios $\mathrm{X}$ e uma microscopia eletrônica de varredura (MEV) nos corpos de prova pós-queima que se enquadram na norma acima, para a visualização das fases cristalinas formadas durante a queima, e a morfologia da superfície desses corpos de prova após a queima.

Tabela 1. Formulações com os resíduos de caulim, granito e polimento do porcelanato

\begin{tabular}{cccc} 
Matérias-primas & Resíduo de caulim (RC) & Resíduo de granito (RG) & $\begin{array}{c}\text { Resíduo de } \\
\text { porcelanato (RP) }\end{array}$ \\
\cline { 2 - 4 } & & \%, em peso & 33,3 \\
MP1 & 33,3 & 33,3 & 30,0 \\
MP2 & 40,0 & 30,0 & 25,0 \\
MP3 & 50,0 & 25,0 & 20,0 \\
MP4 & 60,0 & 20,0 & 10,0 \\
MP5 & 60,0 & 30,0 & 30,0 \\
MP6 & 60,0 & 10,0 & \\
\hline
\end{tabular}

\section{RESULTADOS E DISCUSSÃo}

\subsection{Análise de Fases por Difração de Raios X}

A Fig.1 ilustra os difratogramas dos três resíduos. Para o resíduo de caulim (Fig.1a), foram identificados os picos referentes ao quartzo $\left(\mathrm{SiO}_{2}\right)$, caulinita $\left(\mathrm{Al}_{2} \mathrm{Si}_{2} \mathrm{O}_{5}(\mathrm{OH})_{4}\right)$ e mica $\left(\mathrm{KAl}_{2}\left(\mathrm{Si}_{3} \mathrm{Al}\right) \mathrm{O}_{10}(\mathrm{OH}, \mathrm{F})_{2}\right.$. Resultados semelhantes foram identificados por Varela et al. [19] e Castro et al. [20] em estudos com resíduos de caulim. O resíduo de granito (Fig. 1b), apresentou picos de quartzo $\left(\mathrm{SiO}_{2}\right)$, mica $\left(\mathrm{KAl}_{2}\left(\mathrm{Si}_{3} \mathrm{Al}\right) \mathrm{O}_{10}(\mathrm{OH}, \mathrm{F})_{2}\right)$, anortita (feldspato cálcico, $\left.\mathrm{CaAlSi}_{3} \mathrm{O}_{8}\right)$ e magnesioblenda $\left(\mathrm{Ca}_{2}\left(\mathrm{Mg}_{1} \mathrm{Fe}^{+2}\right)_{4} \mathrm{Al}\left(\mathrm{Si}_{7} \mathrm{Al}\right) \mathrm{O}_{22}(\mathrm{OH}, \mathrm{F})_{2}\right)$. Para O resíduo de porcelanato (Fig.1C), picos referentes a mulita, quartzo e carbeto de silício (SiC) foram identificados. O quartzo e a mulita são provenientes da peça de porcelanato desbastada, enquanto que a presença do SiC está relacionada ao abrasivo utilizado [7].
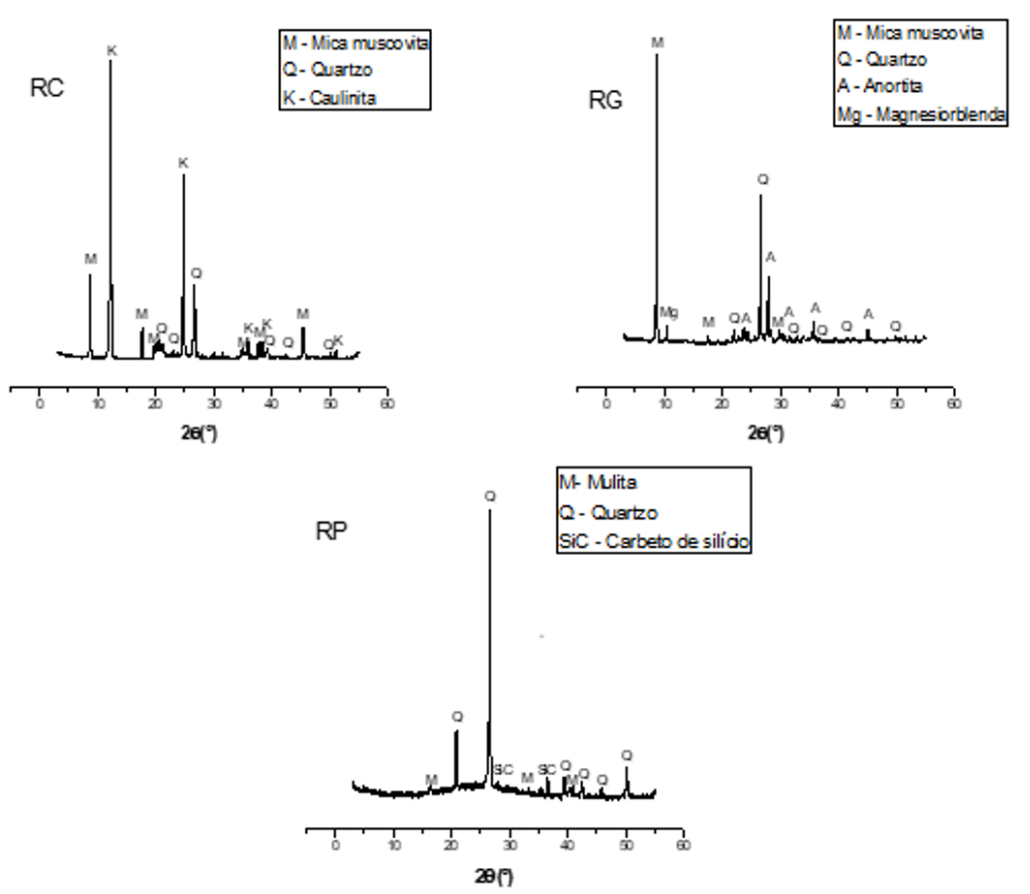

Figura 1. Difratogramas de raios $X$ das amostras de resíduos de: (a) caulim; (b) granito; (c) polimento do porcelanato 


\subsection{Composição Química por Fluorescência de Raios X (FRX)}

A Tab.2 apresenta a composição química dos resíduos de caulim, granito e polimento do porcelanato. $\mathrm{O}$ resíduo de caulim contém $\mathrm{SiO}_{2}$ e $\mathrm{Al}_{2} \mathrm{O}_{3}$ como principais constituintes. O conteúdo dos possíveis óxidos fundentes $\left(\mathrm{Fe}_{2} \mathrm{O}_{3^{\prime}} \mathrm{K}_{2} \mathrm{O}\right.$ e $\left.\mathrm{Na}_{2} \mathrm{O}\right)$ é relativamente baixo. Devido ao alto teor de $\mathrm{Al}_{2} \mathrm{O}_{3}$ em relação a $\mathrm{Fe}_{2} \mathrm{O}_{3^{\prime}} \mathrm{K}_{2} \mathrm{O}$ e $\mathrm{Na}_{2} \mathrm{O}$, a fase líquida formada durante o processo de sinterização se comporta como uma fase líquida de alta viscosidade ou uma fase transiente, o que é desejável para a obtenção de produtos com propriedades físicas e mecânicas mais elevadas. O resíduo de caulim apresentou uma maior perda ao fogo em comparação com os outros resíduos, por apresentar uma maior quantidade de argilominerais cauliníticos (constituintes de menores dimensões). O resíduo de granito apresentou elevados teores de $\mathrm{SiO}_{2^{\prime}} \mathrm{Al}_{2} \mathrm{O}_{3^{\prime}} \mathrm{Fe}_{2} \mathrm{O}_{3}$ e $\mathrm{CaO}$. A elevada quantidade de $\mathrm{SiO}_{2}$ está associada com a fase cristalina do quartzo. O óxido de ferro e o óxido de cálcio foram provenientes, provavelmente, da granalha de ferro e da cal moída, utilizadas nas etapas de corte e polimento de rochas graníticas. Com relação ao uso cerâmico, o elevado teor de ferro $\left(\mathrm{Fe}_{2} \mathrm{O}_{3}\right)$ presente no resíduo de granito, conduzirá coloração avermelhada em peças sinterizadas. Estes óxidos são muito importantes nas formulações cerâmicas, pois podem atuar como agentes fundentes. O resíduo do polimento do porcelanato apresenta elevadas quantidades de óxido de silício, óxido de alumínio e óxido de magnésio. $O$ óxido de magnésio apresentou elevados teores provavelmente oriundo do abrasivo magnesiano utilizado para o polimento. Dessa forma, pode-se afirmar que o resíduo é composto principalmente pela própria massa do porcelanato e pelo resíduo gerado pelo polidor, ambos na etapa de polimento.

Tabela 2. Composição química das amostras de resíduos

\begin{tabular}{ccccccccccc}
\multicolumn{10}{c}{ Óxidos presentes (\%) } \\
\hline & $\mathbf{S i O}_{\mathbf{2}}$ & $\mathbf{A l}_{\mathbf{2}} \mathbf{O}_{\mathbf{3}}$ & $\mathbf{F e}_{\mathbf{2}} \mathbf{O}_{\mathbf{3}}$ & $\mathbf{M g O}$ & $\mathbf{C a O}$ & $\mathbf{K}_{\mathbf{2}} \mathbf{O}$ & $\mathbf{N a}_{\mathbf{2}} \mathbf{O}$ & Outros & $\mathbf{P F}$ \\
$\mathrm{RC}$ & 55,84 & 26,20 & 0,47 & 0,32 & 0,28 & 0,94 & 0,77 & 1,08 & 14,10 \\
$\mathrm{RG}$ & 59,65 & 12,72 & 11,16 & 3,07 & 6,12 & 0,67 & 2,91 & 2,45 & 1,25 \\
$\mathrm{RP}$ & 67,80 & 11,72 & 0,60 & 3,60 & 1,34 & 0,66 & 1,54 & 1,01 & 11,73 \\
\hline
\end{tabular}

Comparando com o seu DRX, afirma-se que o teor de $\mathrm{K}_{2} \mathrm{O}$ observado nos resultados de FRX para o resíduo de granito são oriundos basicamente da mica muscovita, enquanto que o CaO é oriundo do feldspato cálcico, mas principalmente da adição de granalha e óxido de cálcio (atuante como abrasivo), e do lubrificante no processo de corte/serragem. A maior quantidade de $\mathrm{Al}_{2} \mathrm{O}_{3}$ para o resíduo de caulim está relacionado com o argilomineral caulinita, como observado no DRX. O resíduo do polimento do porcelanato apresentou elevada quantidade de $\mathrm{SiO}_{2^{\prime}}$ apresentando um pico bem intenso no DRX.

\subsection{Análise Termogravimétrica (TG) e Análise Térmica diferencial (DTA)}

A Fig.2 ilustra as curvas de análise termogravimétrica (TG) e termodiferencial (DTA) para os resíduos de caulim, granito e porcelanato. O resíduo de caulim apresentou um pico por volta de $560^{\circ} \mathrm{C}$, relacionado à desidroxilação da caulinita e outro em torno de $980^{\circ} \mathrm{C}$, associado à formação da prémulita [21,22]. O resíduo de granito apresentou um pequeno pico endotérmico a aproximadamente $560^{\circ} \mathrm{C}$, associado a transformação alfa-beta do quartzo, picos endotérmicos a 660 e $760^{\circ} \mathrm{C}$ relacionados a desidroxilação e recristalização da mica, respectivamente, e uma banda de aproximadamente 840 a $950^{\circ} \mathrm{C}$, possivelmente relacionada à decomposição do carbonato de cálcio. Já o resíduo do polimento do porcelanato apresentou uma banda endotérmica a $140^{\circ} \mathrm{C}$, o que indica perda de água livre, um pequeno pico endotérmico a aproximadamente $580^{\circ} \mathrm{C}$ relacionado a transformação do quartzo e uma banda de aproximadamente 850 a $1000^{\circ} \mathrm{C}$ possivelmente relacionada ao início da decomposição do carbeto de silício $(\mathrm{SiC})$, formando óxido de silício $\left(\mathrm{SiO}_{2}\right)$ e dióxido de carbono $\left(\mathrm{CO}_{2}\right)$. Constata-se nas curvas termogravimétricas que a maior perda de massa é do resíduo do caulim por serem constituídos pelo argilomineral caulinita, conforme resultado apresentado anteriormente. 

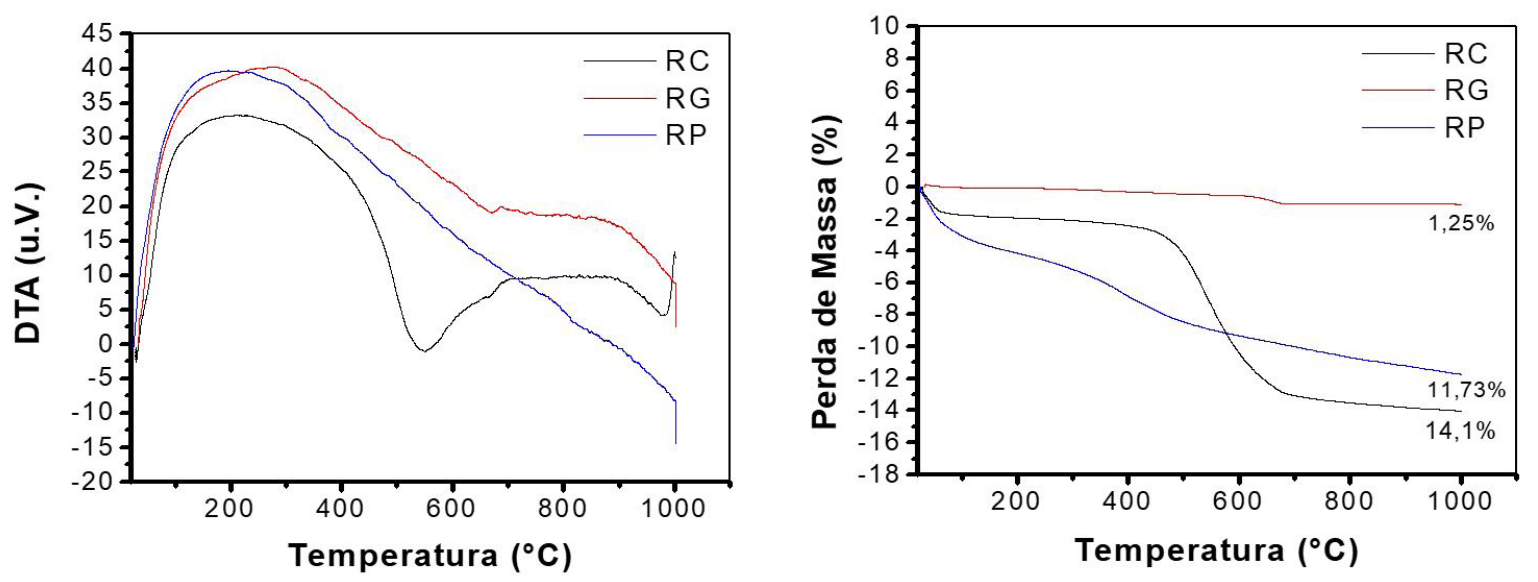

Figura 2. Análise térmica das amostras de resíduos. (a) análise termogravimétrica; (b) análise termodiferencial.

\subsection{Análise Granulométrica}

A Fig.3 ilustra as curvas granulométricas dos resíduos. Observa-se que todos os resíduos apresentaram uma distribuição granulométrica denominada monomodal, mudando apenas o local do pico granulométrico de maior concentração de partículas. O RP apresentou o menor diâmetro médio de $12,71 \mu \mathrm{m}$, enquanto que o RC, com diâmetro médio de $95,42 \mu \mathrm{m}$, o maior, já o resíduo de granito (RG) apresentou um diâmetro médio de $31,76 \mu \mathrm{m}$. O resíduo de caulim apresentou maior diâmetro médio quando comparados com os resíduos de granito e do porcelanato, possivelmente por apresentarem maiores quantidades de partículas finas, que se aglomeram, "mascarando" o tamanho real do diâmetro médio. Observa-se uma faixa de distribuição de tamanho de partículas significativamente homogênea para todos os resíduos, e estão coerentes com faixas granulométricas de matérias-primas utilizadas para fabricação de materiais cerâmicos, segundo a norma NBR 6502 [23].
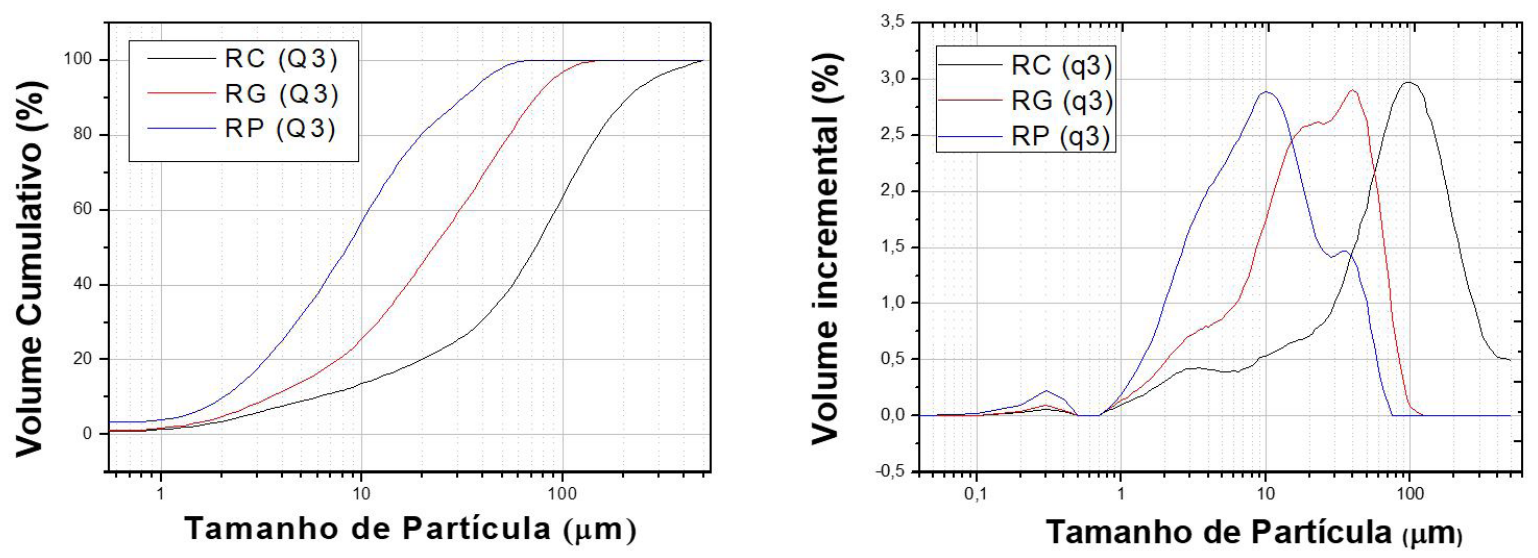

Figura 3. Curvas granulométricas das amostras de resíduos. (a) volume acumulado passante; (b) distribuição do tamanho de partículas.

\subsection{Propriedades Tecnológicas das Formulações}

A Fig.4 ilustra as propriedades tecnológicas das formulações com os resíduos RC, RG e RP, sinterizados nas temperaturas 1000,1100 e $1150^{\circ} \mathrm{C}$. Observa-se que absorção de água, (Fig.4a) sofre uma gradativa redução com o aumento da temperatura para todas as formulações dos resíduos. As formulações MP3 e MP4 apresentaram os menores valores de absorção de água quando sinterizados a $1150^{\circ} \mathrm{C}$. Este comportamento deve-se a alumina presente no resíduo de caulim, contribuindo na formação vítrea do tipo sílico-aluminosa, quando se encontra associado com os óxidos fundentes dos resíduos de granito e porcelanato, auxiliando na formação de fase líquida. A formulação MP6 apresentou maior 
perda de massa e maior retração linear (Fig.4b e c) por apresentar maiores frações do argilomineral caulinita presentes no resíduo de caulim e menores tamanhos de partículas presentes no resíduo de porcelanato influenciando na sinterização. Como foi observado nas análises térmicas, o resíduo do caulim foi o que apresentou maior perda de massa, seguido do resíduo do porcelanato, logo, é justificável que as amostras que contenham a maior quantidade desses resíduos tenham maiores perdas ao fogo. No gráfico da retração linear é possível verificar que apenas as amostras MP5 e MP6 sofreram totalmente retração desde 1000 até $1150^{\circ} \mathrm{C}$, já as demais amostras sofreram retração entre 1000 e $1100^{\circ} \mathrm{C}$, mas entre 1100 e $1150^{\circ} \mathrm{C}$ sofreram expansão. O comportamento pode ser explicado da seguinte maneira: as amostras MP4, MP5 e MP6 foram as que apresentaram maior quantidade de resíduo do caulim (60\%). No entanto, o que pode ter levado a expansão da MP4 é a relação proporcional entre os resíduos de caulim, granito e o resíduo do polimento do porcelanato formando excesso de fase líquida durante a queima.

A Fig.4d apresenta a resistência mecânica à flexão dos resíduos. Observa-se que a resistência é crescente com o aumento da temperatura. As formulações MP3 e MP2 apresentaram os maiores valores de resistências nas temperaturas de 1100 e $1150^{\circ} \mathrm{C}$. Esse aumento deve-se a elevadas quantidades de feldspato cálcico (anortita) presente no resíduo de granito e mica presentes nos resíduos de caulim e granito. A formulação MP6 apresentou maior resistência na temperatura de $1150^{\circ} \mathrm{C}$, por apresentar uma melhor relação entre os óxidos fundentes presentes no resíduo do polimento do porcelanato e o argilomineral caulinita presente no resíduo do caulim. O MP1 apresentou menor resistência à flexão, provavelmente por apresentar excesso de fase líquida e, consequentemente, aprisionamento dos gases residuais da queima.
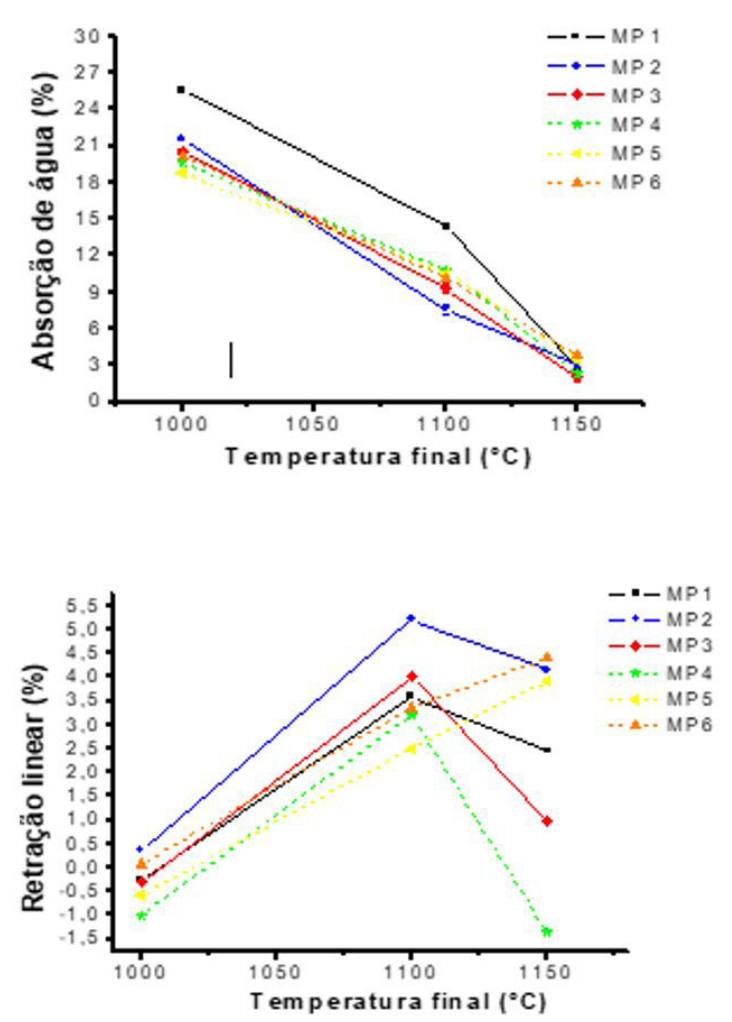
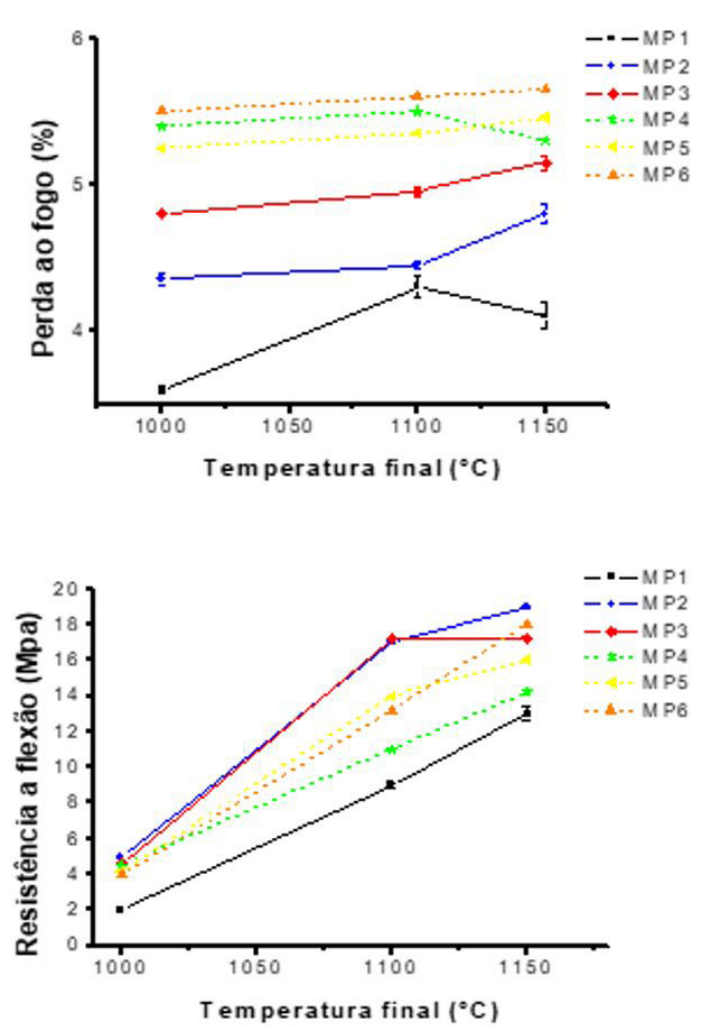

Figura 4: Gráfico das propriedades tecnológicas das amostras de resíduos em função da temperatura final de sinterização 1000,1100 e $1150^{\circ} \mathrm{C}$. (a) absorção de água; (b) perda ao fogo; (c) retração linear; (d) resistência à flexão.

\subsection{Difratogramas das Formulações}

A Fig.5 ilustra os difratogramas das formulações MP2, MP3 e MP6 que foram escolhidas por apresentarem os melhores resultados das propriedades tecnológicas e que se enquadraram na 
norma NBR ISO 10545 [24]. Observa-se que a formulação MP2 (Fig.5a) apresentou picos com maiores intensidades para o quartzo $\left(\mathrm{SiO}_{2}\right)$ e feldspato cálcico (anortita, $\left.\mathrm{CaAlSi} \mathrm{O}_{8}\right)$, por apresentar em sua formulação maiores quantidades do resíduo de granito e do polimento do porcelanato, que vão atuar como fundentes, aumentando sua resistência mecânica. A formulação MP3 (Fig.5b) apresentou mesmo comportamento para o ensaio de resistência à flexão nas temperaturas de 1100 e $1150^{\circ} \mathrm{C}$. Este comportamento pode estar relacionado com o equilíbrio entre as fases existentes de mulita, quartzo $\left(\mathrm{SiO}_{2}\right)$ e feldspato cálcico. A formulação MP6 (Fig.5c) apresentou picos intensos de mulita, por apresentar em sua formulação maiores quantidades do resíduo de caulim e do resíduo do polimento do porcelanato, justificando o aumento na resistência à flexão na temperatura de $1150^{\circ} \mathrm{C}$.
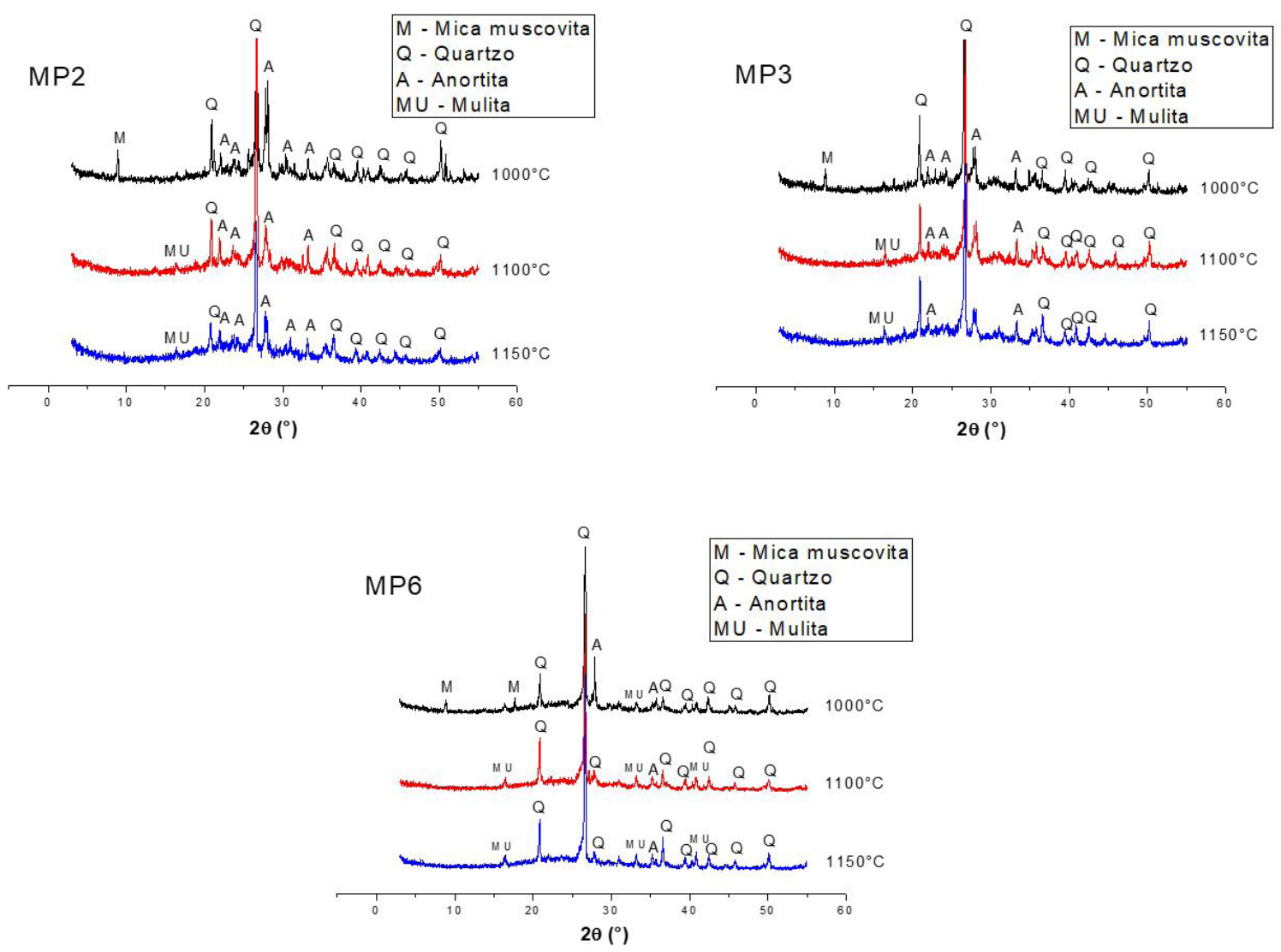

Figura 5. Difratogramas de raios $X$ das formulações que se enquadraram na norma NBR 6502/1995: (a) MP2; (b) MP3; e (c) MP6.

\subsection{Análise por Microscopia Eletrônica de Varredura (MEV)}

A Fig.6 ilustra as micrografias referentes as formulações MP2, MP3 e MP6 sinterizadas a $1150^{\circ} \mathrm{C}$. Os resultados mostram que as formulações MP2 e MP3 (Fig.6a e 6b) apresentaram maiores quantidades de poros. Acredita-se que este efeito pode estar relacionado com a proporcionalidade de 1:1 entre resíduo do porcelanato/resíduo do granito, apresentando um equilíbrio entre fundência e formação de poros e a menor quantidade do argilomineral caulinita presente no resíduo de caulim. $O$ fato de apresentarem a maior quantidade de resíduo do granito que, conforme os resultados de DRX e FRX apresentam uma maior quantidade de quartzo, e pela quantidade de resíduo de caulim utilizado que, devido a sua maior granulometria, favorece a formação de poros interconectados, faz com que haja uma tendência de maior porosidade aparente. A formulação MP6 (Figura 6c) apresentou fissuras na sua estrutura. Este comportamento pode estar relacionado com a queima do resíduo de polimento de porcelanato a temperaturas a partir de $1000^{\circ} \mathrm{C}$, provocando a decomposição do carbeto de silício ( $\mathrm{SiC})$, proveniente do resíduo, em sílica $\left(\mathrm{SiO}_{2}\right)$ e dióxido de carbono $\left(\mathrm{CO}_{2}\right)$ [25]. Através da queima 
rápida, a liberação de $\mathrm{CO}_{2}$ gera elevadas fissuras no interior das peças cerâmicas justificando sua maior perda ao fogo e absorção de água comparada com MP2 e MP3. A MP2 apresentou poros de menor tamanho e formatos mais circulares, o que evidencia uma melhor sinterização. Este comportamento pode estar associado a uma proporção ideal de materiais fundentes oriundos da mica muscovita presente no resíduo de caulim e da anortita, gerando uma sinterização em temperatura mais baixa e formando um corpo mais denso, o que fortemente evidencia maior sinterização, conforme verificado nos picos de maiores intensidades no difratograma da formulação MP2 (Fig.5a).
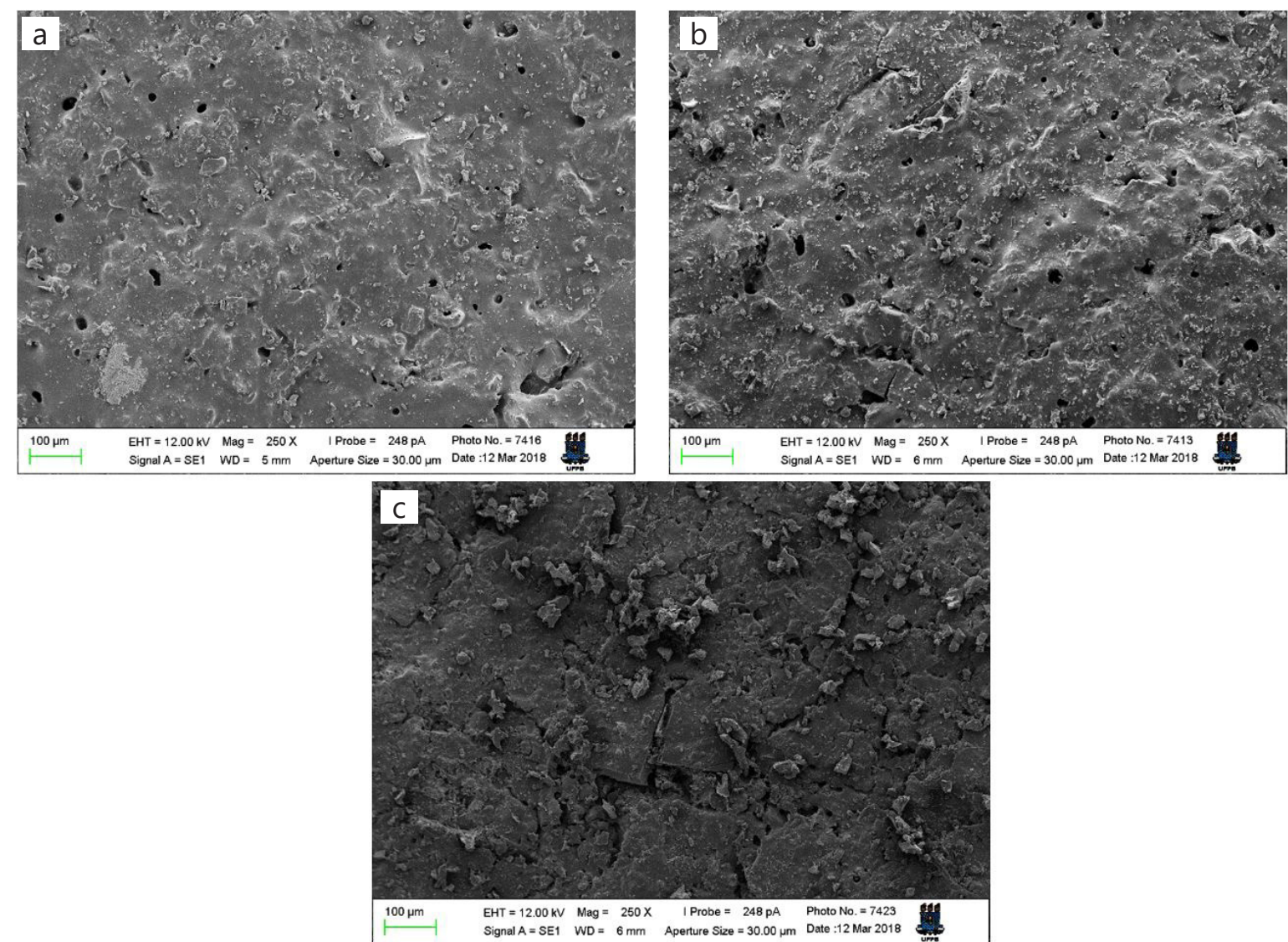

Figura 6: MEV das formulações que se enquadraram na norma NBR 6502/1995 pós-queima sinterizadas a $1150^{\circ} \mathrm{C}$ : (a) MP2; (b) MP3; e (c) MP6.

\section{CONCLUSÃO}

Com base nos resultados obtidos pode-se concluir que o resíduo do caulim é constituído por caulinita, mica e quartzo, o resíduo de granito é constituído por quartzo, mica, anortita e magnesioblenda e o resíduo do polimento do porcelanato é constituído por mulita, quartzo e carbeto de silício e que os resíduos apresentam distribuições granulométricas significativamente diferentes. Constatou-se que as formulações apresentaram elevadas proporções de fundentes e quartzo interferindo na estabilidade dimensional dos corpos e na resistência mecânica. O resíduo de caulim é grosseiro, o de granito é intermediário e o de polimento é fino. Proporções diferentes entre esses três tipos de pós produziram uma mistura de pós com fator de empacotamento diferentes e, por consequência, compactados com porosidade também diferentes. Os melhores resultados para absorção de água e resistência mecânica foram para as formulações MP2, MP3 e MP6 sinterizadas a $1150^{\circ} \mathrm{C}$. A melhoria das propriedades mecânicas de cerâmicas tradicionais é o resultado de um balanço entre as quantidades de fases cristalina, vítrea e poros. A quantidade de fase cristalina (mulita) na formulação MP6 melhora a resistência. A baixa porosidade (pequena absorção de água) da formulação MP3 melhora também, entretanto a elevada quantidade de fase líquida (grande expansão a $1150^{\circ} \mathrm{C}$ ) é um fator negativo. 
A formulação MP2 parece ser a mais bem balanceada já que apresenta a maior resistência mecânica, associada a uma absorção de água intermediária e retração linear "elevada". De modo geral, a obtenção de cerâmicas de revestimento é possível até uma determinada proporção dos três diferentes resíduos industriais.

As formulações estudadas neste trabalho, nas diferentes proporções e temperaturas de sinterização, geraram produtos que podem ser classificados, segundo a norma ABNT NBR ISO 10545-2:2020, em Bllb da classe semi-poroso e Blll da classe poroso, o que confirma que os resíduos estudados, e as combinações deles, têm propriedades que os tornam aptos a serem aplicados em revestimentos cerâmicos, gerando novos produtos à base de resíduos para serem utilizados na indústria da construção civil, os quais, anteriormente, poderiam ser descartados em lugares inapropriados, contaminando solos, rios e lençóis freáticos, além de causar danos a população circunvizinha desses locais de descarte, ou poderiam ser descartados em aterros, conforme a lei $n^{\circ}$. 12.305, de 02 de agosto de 2010, que institui a política nacional de resíduos sólidos, gerando custos aos empresários.

\section{REFERÊNCIAS}

[1] Gualtieri, A.F; Tartaglia, A. Thermal decomposition of asbestos and recycling in traditional ceramics. Journal of The European Ceramic Society, v.20, n.9, p. 1409-1418, ago. 2000.

[2] Menezes, R.R.; Neves, G.A.; Ferreira, H.C. State of the art about the use of wastes as alternative to ceramic raw materials. Revista Brasileira de Engenharia Agrícola e Ambiental, v.6. n. 2 p. 303-313, 2002.

[3] Andreola, F.; Barbieri, L.; Lancellotti, I.; Leonelli, C.; Manfredini, T. Recycling of industrial wastes in ceramic manufacturing: State of art and glass case studies. Ceramics International. V. 42 (12), p. 13333-13338. 2016.

[4] Barata, M.S.; Dal Molin, D.C.C. Preliminary evaluation of the kaolinitic residue of the kaolin processing industries as raw material in the production of a highly reactive metakaolinite - Ambiente Construído, Porto Alegre, v.2, n. 1, jan./mar, p. 69 - 78, 2002.

[5] Barrachina, E.; Esquinas, M.; Llop, J.; Notari, M.D.; Carda, J.B. Development of a glass-ceramic glaze formulated from industrial residues to improve the mechanical properties of the porcelain stoneware tiles. Materials Letters, v. 220, p. 226-228, jun. 2018.

[6] Filho, H. F. M.; Polivanov, H. Mothé, C. G. Recycling: the case of waste of the dimension stones. Anuário do instituo de Geociências, UFRJ, v. 28-2/2005, p. 139-151, 2005.

[7] Marques, L. N., Menezes, R. R., Neves, G. A., Santana, L.N.L., Lira, H. L., Ferreira, H.C. Reuse of porcelain polishing residue for use in cermaic mass. Revista Eletrônica de Materiais e Processos, v.2, p.34-42, 20070.

[8] Lima, R.C.O., Lira, H.L., Neves, G.A., Silva, M.C., Silva, C.D. Use of granite sawdust residue for manufacturing low-cost ceramic membranes.Revista Eletrônica de Materiais e Processos, v.6. n. 3 p. 163-169, 2011.

[9] Constantino, A. O.; Rosa, S. E. S.; Corrêa, A. R.; Panoramas Do Setor De Revestimento Cerâmico, 2006, disponível em <http:// www.bndes.gov.br/siteBNDES/exports/sites/default/bndes_pt/Galerias/Arquivos/conhecimento/relato/rs_rev_ceramicos.pdf>.

[10] Hoffmann, F. S.; Santos, G.; Morelli, M. R. Estudo de fundente e argilito com potencial para uso em formulações de porcelanato. Cerâmica, v.58, n.346, p.174-185, 2012.

[11] ANFACER (São Paulo). Associação Nacional dos Fabricantes de Cerâmica para Revestimento. 2020. Disponível em: https:/l www.anfacer.org.br/setor-ceramico/numeros-do-setor. Acesso em: 10 out. 2020.

[12] Medeiros, E. N. M; Sposto, R. M.; Neves, G.A., Menezes, R. R., Grog incorporation in ceramic mass to manufacture of bricks. A study of the physical-mechanical properties. Revista Cerâmica, v.56, n.340, p. 399-404. 2010.

[13] Betioli, A. M.; Fortunato, M.; Martins, B. R.; Casali, J. M.; Rocha, J. C.; Collodetti, G. Efeito da composição granulométrica e da área superficial específica de resíduos de polimento de porcelanato em argamassas autoadensáveis. Ambiente Construído, v. 20, n. 3, p. 385-402, jul. 2020.

[14] Campos, L. F. A.; Menezes, R.R.; Lisboa, D.; Santana, L.N.L.; Neves, G.A.; Ferreira, H.C. Experimental design to maximize the waste content in ceramic bricks and tiles. Revista Cerâmica v.53, n. 328, out./dez. 2007.

[15] Almeida, L. L. P.; Carreiro, R. S.; Zulo, L. S. N.; Petrucci, L. J.; Pessanha, E. M. Influence of Residue Incorporation on the Properties of Construction Technology for the Mass Production of Pottery Red. In: Eighth International Latin American Conference on Powder Technology- PTECH, Florianópolis, v.1. p.1-6, 2011.

[16] Breitenbach, S.B.; Santos, O.C.; Andrade, J.C.S.; Nascimento, R.M.; Martinelli, A.E. Addition of porcelain tile polishing residue in lime mortars for restoration. Revista Cerâmica v.63, n. 367, jul./set. 2017.

[17] Menezes, R.R.; Neves, G.A.; Souza, J.; Melo, W.A.; Ferreira, H.S.; Ferreira, H.C. Pozzolanic activity of kaolin processing residues for use in masonry mortars. Revista Brasileira de Engenharia Agrícola e Ambiental, v.13, n.6, p.795-801, nov./dez, 2009.

[18] Dantas, A.P.A., Acchar, W., Leite, J.Y.P., Araújo, F.S.D. Use of ornamental stone residues in the production of white ceramics. Holos, v. 1, n. 26, 2010.

[19] Varela, M.L.; Formiga, F.L.; Dutra; R.P.S.; Nascimento, R.M.; Paskocimas; C.A. Influence of kaolin waste addition on technological properties of a standard stoneware formulation produced in industrial scale. Revista Cerâmica, v.55, p. 209-215, 2009.

[20] Castro, R.J.S.; Soares, R.A.L.; Nascimento, R.M.; Bison, E.C. Study of the effect of feldspar and kaolin residue on the production of ceramic coating. Cerâmica Industrial v.20, n.1, jan./fev. 2015.

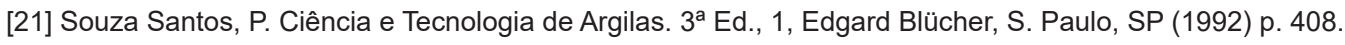


[22] Schwerzler Gi. Recycling of glaze waste through hydrocyclone separation. Powder Technology, v.160(2), p.135-140, 2005.

[23] ABNT NBR 6502:1995: Rochas e solos. Terminologia. São Paulo: Associação Brasileira de Normas Técnicas,1995.

[24] ABNT NBR ISO 10545-2:2020: Placas Cerâmicas Parte 2: Determinação das dimensões e qualidade superficial. São Paulo: Associação Brasileira de Normas Técnicas, 2020.

[25] Bernardin, A.M.; Silva, M.J.; Felisberto, D.S.; Riella, H.G. Characterization of cellular ceramics made by porcelain tile residues. Materials Science and Engineering, n.437, p. 222 - 225, jul, 2006. 